\title{
Al margen de las maravillas (Otros tópicos del cuento popular)
}

\author{
CONSTANTINO CONTRERAS OYARZÚN, \\ MARIO BERNALES LILLO \\ y LUIS DE LA BARRA ARROYO \\ Universidad de La Frontera. \\ Temuco, Chile.
}

\section{RESUMEN}

Los autores estudian un grupo de cuentos de tradición oral registrados en la región de la Araucanía y particularmente en el área cordillerana de Nahuelbuta (centro-sur de Chile). Viejos cuentos hispano-europeos reviven en estas versiones, que se caracterizan por estar estructuradas en torno a los temas del ingenio y la ingenuidad y mostrar un claro sentido del humor.

Palabras clave: Cuentos, Tradición oral, Chile, Motivos.

\section{SUMMARY}

The authors discuss a group of traditional oral short stories (folk-tales) collected in the Araucanía region of the central-south section of Chile, specifically in the mountainous area of Nahuelbuta. Old European and Spanish stories are present in these Chilean narratives, characterized for being structured around the topics of naiveness and ingenuity and revealing a clear sense of humor.

Key words: Folk-tales, Oral Tradition, Chile, Motifs.

\section{PRESENTACIÓN GENERAL}

1.1. Por relato popular puede entenderse toda clase de narración practicada en una sociedad poco influida por la educación sistemática y poco influida también, al menos en forma directa, por la cultura del libro. Los grupos humanos que mantienen relatos populares de tipo tradicional, por medio de la oralidad, están ya en estos tiempos en contacto creciente con los patrones culturales que difunde la televisión, pero bastante alejados de los adelantos tecnológicos de la informática y sus efectos globalizadores. Aunque es posible distinguir varias clases de relatos populares (tanto en

RDTP, LVII, 2 (2002): 139-166 
las culturas de colonización como en las vernáculas), este estudio se limitará sólo al comentario analítico de algunas versiones de cuentos tradicionales (de raigambre hispano-europea) recogidas directamente de la oralidad campesina de la IX Región (y parte de la VIII) de Chile, material que forma parte del corpus registrado en el marco de dos investigaciones empíricas: 1) "El cuento oral de raíz hispánica en sectores periféricos de la Araucanía", ya terminada, y 2) "El legado hispánico en la estructura lingüístico-etnográfica del área de Nahuelbutan, en curso ${ }^{1}$. Se tratará de revisar básicamente cómo se estructuran los tópicos del ingenio y la ingenuidad en un grupo reducido de versiones de cuentos no maravillosos, unidos por distintos matices del humor y otros contenidos humanos que han favorecido su aceptación social.

1.2. Los textos orales tradicionales presentan unos rasgos formales de composición que facilitan su retención en la memoria y su recreación. Y, en este sentido, tales relatos no pueden ser tan diferentes de los relatos de creación individual difundidos por medio de la escritura, es decir, de los relatos propiamente literarios. En ambos casos operan ciertamente similares reglas de textualización (Montemayor 1998: 7-12). Hay momentos también en que el texto de tradición oral, o texto folklórico, y el literario se interrelacionan, esto es, momentos en que algunos textos repetidos oralmente son incorporados por determinados autores en su obra para dar mayor variedad a su creación; o, a la inversa, momentos en que el texto escrito por un creador de literatura trasciende el ámbito privado del lector y pasa a ser compartido oralmente por un grupo hasta convertirse en patrimonio colectivo. En algunos casos esas relaciones se pueden confirmar, aun cuando no se precisen fechas ni circunstancias. Pero, sea como fuere, no es menos cierto que la función social de ambas clases de relatos es diferente. Desde el punto de vista de la teoría de la comunicación, el relato escrito está emancipado del emisor y como mensaje está destinado a un receptor individual (el lector); el relato oral, en cambio, es un hecho de comunicación concreta, en que el emisor es el narrador in praesentia y el acto comunicativo es la narración, aunque se desconozca

\footnotetext{
1 Proyecto DIDUFRO n. ${ }^{\circ} 9804$ y Proyecto DIDUFRO EP-2122, financiados por la Dirección de Investigación y Desarrollo de la Universidad de La Frontera. Una versión abreviada del presente artículo, con el título de "El relato popular", fue leída en calidad de ponencia, por el primero de los autores, en el "VI Coloquio Latinoamericano de Humanidades: Identidad, Región y Cultura", evento llevado a cabo durante los días 4, 5 y 6 de septiembre de 2001 en la Universidad del Bío-Bío, sede Chillán (Chile). Ahora se amplía el aspecto analítico y se agregan las versiones de los cuentos involucrados y las correspondientes notas lingüísticas.
} 
la fuente que originó la historia que se cuenta y se desconozcan también las modificaciones que ha sufrido la composición por obra de distintos narradores y a veces por medio de distintas versiones escritas. La narración oral ocurre en una situación específica de tipo social (reunión de amigos, reunión familiar, momentos de descanso después de las faenas agrícolas, animación de los concurrentes a un velorio, etc.) y, obviamente, va dirigida a ese destinatario colectivo que técnicamente se denomina la audiencia.

1.3. En el marco del relato oral, se sabe hoy que en particular la narración de cuentos ha sido durante siglos —al menos en la cultura occidental - básicamente una actividad de campesinos adultos para destinatarios adultos, en tanto que el destinatario infantil es un fenómeno bastante reciente en la historia del género (Pisanty 1995: 56). Así ha ocurrido también en nuestro país. Aunque actualmente esta actividad narrativa esté debilitada, es indudable que durante siglos ha servido de medio de entretenimiento de muchas personas, pero también de aprendizaje de saberes y de sensible forma de cohesión social. Esto es lo que ha sucedido, por ejemplo, en el área de Nahuelbuta (sector noroccidental de la región denominada, no muy acertadamente, Araucanía), territorio cordillerano en que han perdurado formas tradicionales de vida y de expresión cultural heredadas de los colonos que en el pasado se establecieron allí en un largo proceso de luchas fronterizas que condujo al desplazamiento de la población indígena hacia la costa y hacia la precordillera andina y seguramente también hacia el sur.

1.4. Desde comienzos del siglo XVII y durante todo el período colonial y parte del período republicano, el río Bío-Bío fue la frontera entre un área de colonización asegurada de Chile central y el área de la Araucanía, habitada por indígenas no sometidos. La presencia de militares y de evangelizadores abrió de a poco el paso para que se instalaran al sur del Bío Bío, y con ello en Nahuelbuta, núcleos de campesinos hispano-criollos venidos de la zona central del país. Pero este proceso, que fue en sus comienzos esporádico y débil, logró fortaleza y seguridad sólo a partir de fines del siglo XIX, a raíz de la campaña militar llamada "Pacificación de la Araucaníam. Los colonos que se instalaron en Nahuelbuta fueron fundamentalmente familiares de soldados y trabajadores de la tierra, que tenían experiencia en el cultivo del trigo, la vid y productos de chacarería (papas, maíz, hortalizas) (Cf. Cerda-Hegerl 1996). Seguramente esos pobladores conservaban bien las tradiciones de sus antepasados hispanos y gran parte de ese patrimonio es el que se ha mantenido hasta la actualidad. 


\section{TÓPICOS DEL INGENIO Y LA INGENUIDAD. EL HUMOR}

2.1. Una definición bien elaborada de "cuento popular, cuento folklórico o de tradición oral" es la que propone Julio Camarena (1995: 31): "obra en prosa, de creación colectiva, que narra sucesos ficticios y que vive en la tradición oral variando continuamente. Que el cuento oral tenga carácter ficticio no quiere decir que esté desligado de la experiencia real de los narradores (Cf. Pinon 1965: 10). Siempre será posible encontrar proyectados en su materia narrativa, más allá de las características formales y de su valor estético, importantes aspectos de la vida humana (Cf. Sepúlveda 1982; Valdés 1982; Salas 1985, etc.). Y siempre será posible encontrar otras clases de cuentos orales, aparte de los maravillosos, que han sido los más estudiados (Propp 1981). Hay, por ejemplo, algunos cuentos orales, generalmente breves, caracterizados por el tópico central y común del ingenio puesto a prueba. Es interesante verificar cómo en una esfera natural, es decir, lejos de los parámetros mágicos o maravillosos, el hombre hace gala de su ingenio o pone a prueba el ingenio del otro para conseguir un determinado propósito. No es raro el núcleo narrativo consistente en un concurso de adivinanzas, en el cual caen muchos derrotados y se erige como triunfador sólo aquél que puede formular un enigma tan complejo que nadie, ni el rey ni sus consejeros, logra decodificar. En algunos de estos cuentos, el premio que consigue el protagonista, por haber demostrado ingenio, es el matrimonio con la princesa y su consiguiente ascenso social; en otros, la formulación de una adivinanza o acertijo indescifrable es el recurso que permite a un prisionero recuperar su libertad. Se ha verificado la persistencia de cuentecillos de esta clase en la tradición oral de Nahuelbuta, como se ha comprobado en otra ocasión su vigencia en el área rural de la provincia de Osorno (Contreras, Barraza y Álvarez-Santullano 1995). Es evidente que en estos cuentos el ingenio es puesto de relieve, porque es un valor humano digno de ponderación.

2.2. En otro grupo de cuentos, por lo general también breves y de estructura bastante esquemática, lo que resalta como elemento estructurante es la humorada de un pícaro o la ingenuidad de un tonto, y a veces estas dos facetas en forma complementaria. En varios cuentos maravillosos, la ingenuidad suele ser una faceta primaria y externa del héroe, que desaparece en la medida en que éste revela su particular fortaleza mediante las acciones que realiza para conseguir el objeto deseado. Pero esa fuerza, que se expresa en habilidades extraordinarias para superar obstá- 
culos o en el poder de auxiliares virtuosos o de objetos mágicos, es siempre generada por agentes sobrenaturales. En cambio, en los cuentos no maravillosos, el ingenuo no logra vencer obstáculos ni elevarse socialmente frente a los demás. La ingenuidad es la condición que favorece la caída del incauto o el fracaso de quien hace ostentación de algún grado de poder o fortaleza. Y la debilidad del ingenuo es el campo propicio para que la habilidad natural del ingenioso se sobreponga provocando la burla y la situación humorística, como sucede también en la vida cotidiana.

2.3. En un acercamiento conceptual, es sorprendente verificar que los adjetivos ingenioso e ingenuo se remontan a una misma raíz latina (gignere 'engendrar'), pero ya en el propio latín —según Corominas-, el término ingenium se refería a las 'cualidades innatas de alguien'; en cambio, ingenuus sirvió para referirse a la condición de haber 'nacido en el país' (Corominas 1990: 296, s.v. genio; 336, ingenuo). El castellano siguió acentuando las diferencias semánticas. En nuestros días, "tener ingenio" o "Ser ingenioso" equivale a 'tener talento, dar muestras de creatividad'; en cambio, "ser ingenuo" equivale a 'manifestar candidez, simpleza, debilidad de carácter'.

2.4. Otro concepto que es necesario acotar es el de bumor. Como voz castellana, proviene del latín umor, -oris, que significaba 'líquido', en el sentido de 'humores del cuerpo humano', desde donde pasó en la Edad Media a significar 'genio o condición de alguien', componente "que se creía causado por sus jugos vitales" (Corominas 1990: 327-328, s.v. búmedo). De ahí derivan las formas bumorada, bumorismo, bumoristico. En el castellano actual, estos términos - como señala un importante hispanista- se refieren a "todo el complejo de lo jocoso, lo chistoso, lo cómico, o sea todo lo que produce hilaridad" (Beinhauer 1973: 23). No se dispone de una tipología de las situaciones que producen hilaridad, pero las más comunes en los relatos orales parecen estar en las acciones del ingenuo, en las artimañas de un pícaro, en el ingenio para lograr lo inesperado, en la caída del poderoso, en la irrupción de elementos insólitos, etc. El humor en estos cuentos no es unidireccional o monovalente, sino que tiene varias facetas o matices semánticos: en unos casos es un humor puramente lúdico; en otros, un humor malicioso que hace oscilar el sentido de las palabras entre el tabú y el disfemismo; en otros, es un humor sarcástico, un humor que pone en ridículo algunas desmesuradas apetencias humanas. 


\section{Bertoldo EN los CERros De NAHUElbuta}

3.1. Un cuento (o, mejor, cuentecillo, por la sencillez de su composición) recogido en la localidad de San Ramón Central (comuna de Los Sauces), en plena cordillera de Nahuelbuta, presenta un episodio muy simple en torno a un personaje ingenioso llamado Bertoldo. El narrador, don Belarmino Ulloa, campesino de 80 años de edad, cuenta que Bertoldo era también un campesino, un rústico, pero muy ingenioso, tanto que un rey lo llevó a la corte como consejero. Una vez el rey le preguntó cuáles eran las tres enfermedades más peligrosas y él le contestó: "La verídica gangrena, las deudas del tramposo y las falsas promesas del rey". Con ese mensaje tan directo, el monarca al menos tendría que revisar con cierta atención su conducta política. El narrador menciona también a Marcolfa, la esposa de Bertoldo, como una persona inteligente o hábil para descifrar las adivinanzas de la entretención palaciega, como aquélla del agua y el vino, que la reina no podía resolver: "Como no tengo agua, no le ofrezco vino; solamente le puedo ofrecer aguan. La solución que da Marcolfa es que esa adivinanza se refería al dueño de un molino que no tenía agua para moler; por eso no tenía dinero para comprar vino; de modo que a su visitante sólamente le podía ofrecer agua.

3.2. Doña Ana Rosa Larregla Cea, narradora de 82 años de la hijuela Santa Cruz, de Carrizal, localidad enclavada hacia el centro de la cordillera de Nahuelbuta, alude también a Bertoldo y a su esposa Marcolfa como personajes ingeniosos, pero apenas recuerda este episodio de la adivinanza. Sin embargo, todo indica que cuentecillos de Bertoldo tuvieron alguna difusión en esta área (como también nos consta que ha sucedido en Chiloé), difusión alimentada seguramente por el texto escrito, pues se sabe que en el mundo hispánico (y, por extensión, en Latinoamérica) circularon en siglos pasados varias ediciones de Bertoldo, Bertoldino y Cacaseno, texto traducido del original italiano, cuyo autor, Giulio Cesare Della Croce, vivió en pleno siglo XVI (ref. en Vélez 1992). Es posible imaginar cómo Bertoldo y Marcolfa, personajes de ficción, se establecieron en el imaginario de las gentes de Nahuelbuta, donde ahora agonizan, para dejarnos la imagen de quienes son depositarios de la sabiduría popular, aquella sabiduría transmitida de manera espontánea, sin mediación institucional y que, según el principio renacentista de la estimación de lo natural sobre el artificio, podía también influir en las esferas más altas de la sociedad. 


\section{EN aguas de un mismo Río: Chanza de Pedro URdemales}

4.1. Mucho más vitales en el área estudiada son los cuentos en torno a Pedro Urdemales, personaje que, además de ser ingenioso, es un pícaro que se burla de medio mundo y saca ventajas de esas cualidades para superar sus propias flaquezas. Sin embargo, hay ocasiones en que la habilidad de Urdemales se diluye o desaparece como envuelta en el velo de la ingenuidad, de lo que resulta potenciado el humorismo de la aventura. Esto sucede, por ejemplo, en un relato, que apenas alcanza la categoría de cuentecillo (por la simplicidad de su anécdota): Don Otto, Federico y Pedro Urdemales. Este cuentecillo fue narrado por don Roque Orellana Salgado, trabajador agrícola de 71 años de edad, que nació en Traiguén, nunca asistió a la escuela y reside actualmente en la localidad de Quino (comuna de Victoria). El relato narrado por don Roque es indudablemente una versión del cuento hispano-europeo Trayendo agua del pozo (Tipo 1250, Thompson 1972: 261); pero lo singular de la versión local es que reúne a personajes provenientes de tradiciones distintas, unidos por el rasgo común de la ingenuidad: don Otto y Fritz (o Federico), personajes de tantos chistes populares que encarnan el anecdotario atribuido a los colonos alemanes de nuestro país, y Pedro Urdemales, personaje con aires de criollo, pero heredero de la picaresca española. En síntesis, los tres personajes en camino sienten mucha sed; Urdemales propone saciarla, por turnos, porque es difícil alcanzar el agua; sólo se puede acceder a ella mediante una especie de cadena o escalera humana desde un puente. El primero que alcanza a tocarla, por supuesto, es él; pero en ese momento don Otto, que estaba aferrado al puente soportando el mayor peso, estima necesario escupirse las manos. Desde luego, más que saciar su sed, todos se dan un frío chapuzón en el río.

4.2. Por una parte, siguiendo lo que opinan los propios narradores entrevistados, se puede sostener que el personaje Pedro Urdemales es profundamente chileno, porque asume algunos de los rasgos de nuestros campesinos: apego a la tierra y a sus costumbres, buscavidas, servidor de varios señores, astuto, jocoso, burlador, etc. Manuel Dannemann ha señalado que en la mayoría de los relatos concernientes a este personaje aparecen destacados los siguientes rasgos: empleo de la astucia del protagonista para la obtención de sus propósitos y afán de crítica social destinado a denunciar y satirizar defectos profundos, como la avaricia, la ambición desmesurada, la injusticia, el abuso del poder, la codicia, la envidia, la soberbia; aunque cabe reconocer que el segundo [el afán de crítica 
social] se expresa a través de generalizaciones enfáticas ficticias (Dannemann 1985: II, 204).

Por otra parte, no es menos cierto que desde un punto de vista histórico, Urdemales ha heredado varios rasgos de la tradición picaresca española del Siglo de Oro. Por ejemplo, cuando la avaricia y la creencia llegan a límites extremos y se confunden con la ingenuidad, la burla del pícaro no se hace esperar. Se han registrado varios episodios anecdóticos en los que Urdemales obtiene ventajas de la ingenuidad de la gente para superar su propia situación desmedrada.

\section{LA HERENCIA CERVANTINA DE UN PERSONAJE CRIOLLO}

5.1. Esta faceta picaresca aparece muy nítidamente explícita, por ejemplo, en el cuentecillo llamado El cartero del otro mundo (Laval 1997 [1925]: 61-62), del cual hemos registrado unas cinco versiones, por supuesto con variantes, en el área estudiada, particularmente en la localidad de Cunco (al este de Temuco) y en la periferia de Angol y Nacimiento, en narradores procedentes del área de Nahuelbuta. En todas esas versiones, Pedro Urdemales simula tener la misión de traer mensajes del otro mundo y luego llevar mensajes, alimentos y dinero para las almas sufrientes. Los deudos, con la ingenuidad de quienes son incapaces de distinguir el plano físico del metafísico, entregan tales contribuciones a tan singular mensajero y éste desaparece rápidamente para gozar de los beneficios obtenidos de ese modo tan artero. Como esta actitud de Urdemales es un elemento recurrente en varias de sus aventuras, el personaje pasa a ser una especie de símbolo del trabajador trashumante y ocasional, aquél que puede ocuparse temporalmente de labrar la tierra o cuidar la hacienda del patrón por un salario no siempre satisfactorio y que, en el límite de sus carencias, es capaz de utilizar su ingenio para obtener —engañosamente- algunos bienes materiales de quienes gozan de bienestar.

5.2. Es necesario indicar que estas variantes corresponden con seguridad al Tipo 1540 del índice internacional de Aarne-Thompson, conocido con el nombre de El estudiante del Paraíso, del cual Antti Aarne logró reunir y estudiar unas trescientas versiones orales provenientes de países europeos y también de países orientales (Thompson 1972: 229-230). Y algo muy importante también: es indudable que este cuentecillo, según las fuentes disponibles, era conocido ya en el Siglo de Oro español, pues aparece incorporado como episodio en una comedia de Cervantes que lleva por título precisamente el nombre del pícaro, Pedro de Urdemalas. Y se 
sabe que con este nombre circuló, además, otra comedia, hoy inencontrable, atribuida a Lope de Vega (Chevalier 1978: 94-98). No sería extraño que, como otros cuentecillos, éste haya pasado de la oralidad a la literatura, en el sentido más estricto de la creación verbal escrita. El estudioso italiano Paolo Savj-López, al referirse al pasaje de la comedia cervantina en que se desarrolla el motivo del mensajero del otro mundo, dice: "nos divierte escuchar a Pedro, que quiere embrollar a una vieja avara, presentándosele como un alma del purgatorio enviada sobre la tierra para recoger las ofertas de los vivos y hacer así ascender al cielo a sus muertos" (Savj-López 1917: 196). Y con respecto a los rasgos del personaje Urdemalas, que participa en variadas acciones picarescas, el analista destaca su gran versatilidad: cínico, ardiente, astuto, deshecho por la vida, salido incólume de todas las aventuras y pronto a todas las metamorfosis, hijo de nadie, acostumbrado al hambre, diestro en el bien y en el mal, ora mendigo, ora marinero, ora ladrón, ora estudiante, ora gitano, pero siempre sediento de lo imprevisto, siempre arrebatado por la fantasía inquieta (Savj-López 1917: 197).

\section{LA CAÍDA DEL MÁs FUERTE}

6.1. Otro cuento, o mejor cuentecillo, de los más repetidos, es aquél en que Pedro -en apuestas por dinero- acepta los sucesivos desafíos del Diablo o de un gigante, personajes sobrenaturales, pero que desarrollan acciones muy humanas, aunque exageradas en sus posibilidades. En todas las pruebas, generalmente tres o seis, es derrotado quien, ingenuamente, sólo confía en su poder o en su fuerza física; y, en cambio, vence quien, aunque está físicamente en desventaja, se apoya en su ingenio o astucia. Las versiones más completas son las que han entregado dos narradores del área de Nahuelbuta: don Juan Bautista Toledo, trabajador agrícola de la localidad de Cerro Negro, sector de Maitenrehue (comunas de Angol y Nacimiento) y don Pablo Hidalgo Larregla, trabajador agrícola de la localidad de Carrizal (comuna de Nacimiento). En ambas versiones (Las apuestas de Pedro Urdemales y el Diablo y Las apuestas de Pedro y el gigante), este contraste reiterado entre la fuerza física utilizada con ingenuidad por el poderoso y el ingenio empleado burlescamente por el débil es el recurso básico que configura las situaciones humorísticas. A pesar de las diferencias superficiales que presentan dichas versiones, es indudable que coinciden en su estructura profunda. El primer episodio, aquél en que el gigante propone a Pedro la prueba de ir al monte a por leña y queda en desventaja frente al intento de éste de liar o amarrar 
todo el bosque para transportarlo, es coincidente con el que consigna Aurelio M. Espinosa con el no 194 de los Cuentos populares españoles (ver Chevalier 1978: 36-37) y, por otra parte, corresponde al Tipo 1049 del índice internacional: El hacha pesada (ver Thompson 1972: 622 y 275). Al comentar este episodio del cuento, Chevalier encuentra antecedentes clásicos en una frase proverbial consignada por Gonzalo Correas en su Vocabulario de refranes...: "-Pedro de Urdimalas, o todo el monte, o nonadan. Sólo por esta información concluye, sin temor a equívocos, que: «esta aventura de Pedro de Urdemalas pertenecía ya a la leyenda del personaje tal como la conocían los labradores, artesanos e hidalgos de la España del Siglo de Oro" (Chevalier 1978: 36-37).

6.2. La versión oral entregada por don Pablo Hidalgo, con sus seis secuencias bien claras, es la más completa de las que hemos registrado y es bastante parecida a la versión recogida hace algunas décadas, en alguna localidad chilena, por Ramón Laval, con el nombre de Las apuestas con el gigante (Laval 1997 [1925]: 67-73) y sólo el cuarto de los episodios es similar al que aparece en la versión registrada por Y. Pino con el título de Pedro Urdimale y Lucifer (Pino 1963: III-34-36). Todo parece indicar que la versión dada por Hidalgo es una recomposición de varios cuentecillos anecdóticos similares (Tipos $1049+1063+1060+1062+$ 1085, ver Thompson 1972: 622-623). Aunque, estructuralmente, bien se podría considerar también que es el desafío y el cumplimiento de las pruebas un único "motivo" básico y estructurante que reaparece con variantes en cada episodio. En todo caso, la estructura de las acciones, dispuestas en secuencias, se puede esquematizar del siguiente modo:

1) Traer del bosque una gran carga de leña. El gigante consigue llevar al hombro una carga bastante abundante y pesada; pero, ante el intento de Pedro de amarrar todo el bosque para transportarlo, se da por vencido.

2) Acarrear la mayor cantidad de agua de una laguna. El gigante consigue llevar al hombro una pipa de agua; pero, ante el intento de Pedro de abrir un cauce para vaciar la laguna completa, se da por vencido.

3) Moler una piedra con la mano. El gigante aprieta una piedra para molerla y la hace arena. Pedro simula apretar una piedra, pero en realidad aprieta un quesillo. Obviamente, no sólo lo muele, sino que también le extrae el líquido.

4) Tirar una piedra muy lejos. El gigante tira una piedra y alcanza una considerable distancia. En vez de una piedra, Pedro lanza al aire un gorrión que ha ocultado en uno de sus bolsillos y el ave se pierde en la distancia.

5) Dar un puñetazo en un roble y dejar la marca. El gigante da un puñetazo al árbol, tan fuerte que se le llegan a reventar los nudillos. Pedro, que ha abierto previamente un agujero en el tronco, hunde su brazo hasta el codo.

6) Tirar una lanza muy lejos. El gigante tira una lanza hasta alcanzar una enorme distancia. Pedro intenta tirar la lanza para alcanzar a la madre del gigante, que vive en Francia. El gigante lo disuade para que no cometa tal desatino y con ello se da por vencido. 
Si hubiera que reducir a una fórmula simple la estructura profunda de cada una de estas secuencias y la global de la versión, debería quedar representada en ella al menos la desigualdad inicial de ambos personajes, desde una perspectiva física (A/b), para cumplir una tarea (x), y la contrapuesta desigualdad final entre los mismos personajes, desde el punto de vista de su ingenio $(\mathrm{a} / \mathrm{B})$. Siempre el ingenioso busca el modo de vencer al fuerte mediante la introducción de un elemento inesperado, sorpresivo (y): $\mathbf{A} / \mathbf{b}(\mathbf{x}) \longrightarrow \mathbf{a} / \mathbf{B}(\mathbf{x}+\mathbf{y})$.

6.3. El humorismo de este relato reside en las ocurrencias de Pedro para vencer las pruebas difíciles: no hay en esas acciones ninguna maravilla, sino sólo recursos ingeniosos y sorpresivos. Pero el humor, además de surgir de los aspectos formales de la estructura narrativa y su reiteración en forma de una composición alegórica, resulta indudablemente potenciado por los recursos expresivos de tipo lingüístico (y paralingüístico) que emplea el narrador en su propósito de dar vitalidad al relato. Los recursos expresivos empleados por éste, y otros buenos narradores, tienen que ver regularmente con las cualidades del sonido articulado, como son los elementos suprasegmentales de la intensidad y las inflexiones tonales, y con los gestos y ademanes que producen en su arte efectos similares a los de la dramatización. Naturalmente, todos esos efectos empalidecen cuando la narración oral se traslada a la escritura. Sólo como una pequeña muestra, se citará aquí la parte final de la versión comentada:

Después le dijo:

- Mira, Pedro - le dijo-, ahora vamos a ir a la última - le dijo- Y si te gano ésta - le dijo-, estás mal; y si no, estás bien —le dijo-. Ya —le dijo-, vamos a tirar una lanza mañana - le dijo-. iQuién la va a tirar — le dijo- más lejos! Llega el gigante al otro día. Toma una lanza y la tira. ¡Puta!, llegó harto lejos pa(ra) allá pu(es).

Y ya Pedro le dijo:

- Mire, mi gigante — le dijo—, ¿adónde usted —le dijo— tiene la... tiene su mamá? —Puta! - le dijo-, yo la tengo en Francia — le dijo.

- ¡Ya pu(es)! -le dijo.

Y empezó Pedro y tomó la lanza y la batía aquí; le decía:

- ¡Lanza, lanza, ándate pa(ra) Francia!... ip(or d)onde la madre del gigante, a atravesál.le la panza!

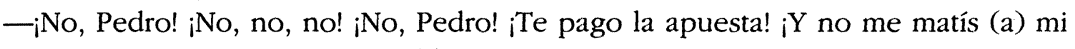
mamá! ¡Cómo me vas a matar (a) mi mamá!

jaa, ja, ja! Así que de ahi se terminó pu(es). Se terminaron las seis apuestas. ja, ja, ja! 


\section{El BURLADOR BURLADO}

7.1. Antes de concluir, parece pertinente comentar otro cuentecillo de este popular personaje, a propósito de una versión recogida también en el área de Nahuelbuta con el nombre de La burla de Pedro Urdemales, versión interesante porque presenta una imagen bastante diferente del protagonista: en su trama narrativa ya no aparece Pedro como el habitual burlador, sino como un incauto burlado, como si sus recreadores (o recreadoras) le hubiesen querido bajar el perfil hasta degradarlo a una especie de ingenuo hazmerreír. Sus elementos básicos permiten verificar que este cuentecillo es una versión del cuento de chanza catalogado en el índice internacional con el nombre de El cambio ventajoso (Tipo 1655), conocido, según Thompson, "desde las islas británicas hasta el Asia Central" (Thompson 1972: 230). Lo particular es que este cuento, relativo a un pícaro y tramposo y una princesa, en Chile es asimilado claramente a las aventuras de Pedro Urdemales. En una versión registrada por Ramón Laval con el nombre de La gallina, esta historia anecdótica de Pedro es bastante sencilla (Laval 1997 [1925]). En la versión narrada por don Mauricio Cid Campos, trabajador agrícola de la localidad de Los Patos (área de Nahuelbuta, comuna de Nacimiento), la historia se extiende algo más con la incorporación de un segundo episodio.

7.2. En síntesis, Pedro que va de viaje, lleva una gallina bajo el brazo, pero, como le causa molestia, pasa a encargarla a la casa de un caballero, con el compromiso de rescatarla muy pronto. Transcurren los días y sobreviene la mala suerte: la gallina muere aplastada por un cerdo. Cuando Pedro vuelve por su encargo, el dueño de casa le explica lo sucedido y quiere pagársela. Pedro no acepta dinero y, en cambio, exige que se le entregue el cerdo. El dueño accede, pero, como el cerdo se vuelve un obstáculo para el viajero, éste lo encarga en casa de otro señor, con el compromiso de rescatarlo muy pronto. Este señor tiene una hija, la cual, en vista de que pasan los días y el dueño no aparece, pide a su padre que mate el cerdo para aprovechar bien su carne; y el padre acepta. Cuando Pedro vuelve por su cerdo, el dueño de casa le explica lo sucedido y quiere pagárselo. Pedro no acepta dinero y, en cambio, exige a la hija como compensación, por haber sido ella la causante directa de la muerte del animal. Después de manifestar cierta resistencia, el padre acepta entregar a la muchacha. La situación no resulta muy grata para ella y Pedro no encuentra nada mejor que transportarla dentro de una bolsa. Por el camino le promete muy buen vivir. Al entrar en un 
almacén a comprar provisiones, deja afuera la bolsa, pasa una señora que escucha gritos que vienen de su interior, la desata, libera a la joven y la suplanta por una perra. Pedro coge la bolsa, se la carga al hombro y sigue dirigiendo buenas palabras a su prometida. Cuando llega a su destino, desata la bolsa y, como no sale la joven, sino la perra, cree que ha sido víctima de brujería.

7.3. Esta síntesis da una idea general de la trama narrativa del cuento, una trama bastante simple y simpática, en cuyo desarrollo se introducen elementos insólitos que lindan en lo absurdo y provocan la risa. Las secuencias o episodios de la gallina, el cerdo, el singular transporte de la muchacha y la suplantación de ésta por la perra son situaciones que no pueden provocar sino una reacción de hilaridad en los destinatarios. A estos episodios, que configuran una progresiva complicación de los sucesos, se añade la resolución o desenlace que marca, en este caso, la degradación o caída del protagonista. Pedro Urdemales, tan pícaro e ingenioso en otros cuentos en éste es víctima de un engaño brutal. Él, que en otros cuentos o cuentecillos que aún gozan de popularidad entre los campesinos, es el ingenioso capaz de engañar al mismo demonio, pero también el burlador de mujeres, el diablillo capaz de humillar al género femenino, sufre un revés: en este cuento es precisamente la mujer quien le da el correspondiente merecido por sus picardías. Los destinatarios descubrirán o construirán el sentido ejemplarizador de esta narración.

7.4. Aparte de la trama de este cuento y de los posibles efectos moralizantes de su contenido, hay que considerar la evaluación, instancia de un texto narrativo que no siempre está explícita, pero que cuando lo está, corresponde a una reacción del narrador frente a lo que ha contado (cf. van Dijk 1992: 155). En efecto, al final de la versión aquí referida, el narrador expresa la siguiente evaluación:

Pero la habilidad de la señora de poner la perra a(d)entro del saco. jJa, ja, ja! Ahí la sacó mal Urdemales, porque él hacía leso al mismo demonio, pero esta vez fue burlado por una mujer.

Este relato y la evaluación que hace de él el mismo narrador, nos están indicando, una vez más, que en el cuento de tradición oral los rasgos de los personajes también pueden variar (e incluso intercambiarse) de acuerdo con las preferencias de los narradores y con las relaciones intertextuales que ellos mismos establecen; que hay rasgos que tienden a permanecer, pero que no son inmutables; así como también las estructuras narrativas del relato oral tienden a mantener su identidad, a través del tiempo, en 
la memoria de los narradores o "cuenteros", pero inevitablemente varían por la intervención de muchos factores, individuales y sociales; como también varían las formas de la lengua hablada, medio privilegiado por el cual adquieren vida estas diversas y variadas historias de la ficción popular.

\section{LAS VERSIONES ESTUDIADAS}

\subsection{Cuento de Bertoldo}

Informante:

Edad:

Escolaridad:

Localidad:

Fuente:

Actividad:

Registro:

Fecha de registro:
Belarmino Ulloa Urra

80 años

básica incompleta

San Ramón Central (comuna de Los Sauces)

Don Belarmino recuerda fragmentariamente lo que le contaba su padre, quien había leído alguna vez el libro de Bertoldo; por su parte, él ha contado oralmente algunas de esas historias a sus hijos y amigos, pero, en forma autocrítica, no se considera un buen narrador.

labores agrícolas

Constantino Contreras y Mario Bernales; acompanante: Jorge Zúñiga (camarógrafo) 27/04/2001.

Bertoldo vivía con su mujer, que se llamaba Marcolfa y su hijo, que se llamaba Bertoldino, en un lugar muy escondido de la montaña. Entonces el rey mandó a buscar a Bertoldo, porque oyó decir que era un hombre inteligente y necesitaba tener un consejero; porque él a veces dudaba entre tomar una decisión o arrepentirse. A los mensajeros les costó mucho encontrar la casa, porque estaba perdida en la montaña. Bertoldo tenía miedo de montar a caballo: se asustaba con el ruido que hacía la bestia cuando mascaba el freno y roía el fierro ${ }^{2}$. Dijo:

- iOh, este animal es un hereje!

Entonces quiso que lo pusieran vuelto para atrás pu(es) ${ }^{3}, \mathrm{pa}(\mathrm{ra})$ no escucharl.le el ruido allá adelante, en las orejas. Y así lo pudieron llevar, porque el rey pidió que lo llevaran a su presencia.Y le costó pa(ra) dar con su casa, porque Bertoldo vivía muy lejos, en medio del monte.

Bertoldino quedó en la casa, con su mamá Marcolfa. Y Bertoldo salió a correr tierras hasta llegar a presencia del rey. Entonces el rey lo sostuvo y le hacía muchas preguntas y to(d)o, porque varias veces dudaba el rey en algunas cosas. Y le

2 fierro: forma con $f$ - inicial conservada, común en el español hablado en Chile, frente a la forma más evolucionada bierro.

${ }^{3}$ Para indicar el debilitamiento o pérdida de unidades fónicas (y ocasionalmente la pérdida de alguna unidad morfológica) se utilizan los paréntesis. 
preguntaba a Bertoldo, que era un simple pájaro de la selva ${ }^{4}$ no más pu(es). En cambio de eso, le daba las respuestas más exactas, que quedaba admira(d)o. Según me recuerdo, una vez el rey le dijo:

- iOye, hombre, bonitos sesos tienes tú! ¡Si se te vieran!

-Y tú, mejor humor tendrías si no comieras - le contestó Bertoldo.

Cuando ya lo conoció, después de algún tiempo le preguntó:

- ¿Cuáles son las enfermedades que más cunden en la persona?

-Tú lo sabes mejor que yo - le dijo Bertoldo.

-No - le dijo el rey-, por eso te pregunto.

- Bueno, yo te voy a decir la verdad bien claramente - le dijo-: la verídica gangrena, las deudas del tramposo y las falsas promesas del rey.

Se quedó el rey pasma(d)o, porque él le contestó bien pu(es)

$\mathrm{Y}$ eso le causó gran deseo al rey de mantener a Bertoldo en la ciudad, en la corte. Por eso mandó a buscar también a Marcolfa y Bertoldino. Y Marcolfa también era inteligente pu(es). Una vez la reina estaba jugando y para recuperar una prenda tenía que resolver una adivinanza. Como no podía encontrarle el significado, le pidió ayuda a Marcolfa:

- ¿Cuál puede ser el contenido de esta adivinanza - le dijo-: "Como no tengo agua, no le ofrezco vino; solamente le puedo ofrecer agua".

Marcolfa conocía qué significaba, porque la había escuchado entre los campesinos.

-Es fácil -le dijo-. Se trata del dueño de un molino que no tenía agua para moler; por eso no tenía dinero para comprar vino. A una visita no le podía ofrecer vino; solamente le podía ofrecer agua.

Claro, para ella era fácil, porque conocía la adivinanza.

Después que murieron Bertoldo y Marcolfa, quedó cerca del rey su hijo Bertoldino. Y Bertoldino ya tuvo descendencia también: tuvo un hijo, que se llamó Cacaseno.

\subsection{Don Otto, Federico y Pedro Urdemales}

Narrador:

Roque Orellana Salgado

Edad:

71 años

Escolaridad:

no tiene

Actividad:

labores agrícolas

Localidad:

nació en Traiguén, pero reside en Quino (comuna de Victoria) desde los 6 años de edad

Fuente: aprendió varios cuentos de boca de narradores adultos en 1958, cuando estuvo enfermo en el Hospital de Traiguén

Registro: Constantino Contreras y Luis de la Barra

Fecha de registro: $12 / 06 / 98$.

Don Otto y Federico eran compadres. $\mathrm{Y}$ se encuentran un día con Pedro Urdemales pu(es). Entonces Pedro Urdemales quería salir a cazar y no tenía compañeros pa(ra) salir a cazar pu(es) pajaritos al campo. Entonces se encuentra con

\footnotetext{
${ }_{4}^{4}$ pájaro de la selva: expresión metafórica para destacar la rusticidad del personaje.
} 
los compadres que siempre andaban juntos: don Otto y Federico. Entonces Pedro Urdemales le(s) dijo:

-Oye, Federico, Otto, necesito que me acompañen pa(ra) ir al campo a buscar perdices, a cazar lo que encontremos.

- ¿Cierto? - dijeron los otros.

一 ¡Sí pu(es)!

— ¡Ya pu(es)! —dijeron—, ¡vamos!

Así que salieron al campo los tres: Federico, don Otto y Pedro Urdemales; salieron al campo. Anduvieron un buen poco ${ }^{5}$. Cazaron una perdiz. Pero era harto poco. Entonces habían andado un buen poco. Y hacía calor. Y no había agua, a(d)ónde tomar agua. $Y$ anduvieron otro poco. ¡Y que no ${ }^{6}$ había un chorrillo angosto!; pero tenía profundo como tres metros de profundidad; pero era angosto un canal que había. Y había un puente donde pasaba - pa(ra) allá, para acáel público. Y ahi entonces había agua pu(es).

$\mathrm{Y}$ ahi $^{7}$ dijeron:

-Ahí hay agua, pero está harto abajo.

- ¿Cómo tomamos, si no tenimos ${ }^{8}$ en qué bajar?

Entonces Pedro Urdemales, como era medio malón ${ }^{9}$, le(s) dijo:

-Otto se toma de las basas del puente; Federico - dijo- se baja por Otto y se toma de él. Y yo me bajo por ustedes - le(s) dijo- y tomo agua. Y después - dijo- hacimos el cambio: entonces baja uno de ustedes a tomar agua...

- También es cierto - dijeron los otros-. También es cierto. Podimos tomar agua así.

Entonces llegaron a un acuerdo:

- Ya, Otto se va a tomar del puente; Federico sigue de Otto y se toma de los pies; y yo me voy a seguir...

Ya. Entonces Otto se allegó y se pescó de las basas del puente y esperó. En seguida Otto estaba muy tomado de ahí. Federico pasó del lado de Otto pa(ra) abajo y se tomó de él, abajo. Y en seguida viene el otro, Pedro Urdemales. Dijo:

- Yo voy a tomar agua primero.

Entonces baja por el la(d)o de los otros. Y cuando Pedro Urdemales estaba allá colgando cerquita ${ }^{10}$ del agua, entonces Otto le(s) dijo:

5 un buen poco: locución adverbial equivalente a 'bastante'; en cambio, harto poco equivale a 'muy poco'.

${ }^{6}$ Nótese que el uso de la forma adverbial no en ciertos contextos admirativos, sirve, paradojalmente, para expresar la certeza de algo positivo.

$7 a b i$ : es variante fónica, monosilábica, de $a b i$, por la tendencia antihiática, frecuente en el castellano hablado en Chile.

8 tenimos: Las variantes morfológicas tenimos, hacimos y podimos (de primera persona de plural, presente de indicativo), que aparecen en este relato, son formas de verbos en -er asimiladas a las correlativas de los verbos terminados en -ir (como salimos, subimos, etc.).

9 malón: en este contexto es forma aumentativa del adjetivo malo.

${ }^{10}$ cerquita: El empleo de cerquita y poquito en esta narración revela que la tendencia al empleo del diminutivo no es exclusiva de las formas nominales; alcanza también a algunos adverbios. 
- iA ver! ¡Espérense un poquito, porque yo me voy a escupir las manos!

Bueno, se larga del puente pa(ra) escupirse las manos y caen los tres al agua. Ahí quedaron todos amontona(d)os tomando agua. Ahí quedaron todos juntos; no había pa(ra) qué hacer escalera.

\subsection{El viajero del otro mundo}

Informante:

Edad:

Escolaridad:

Actividad:

Localidad:

Fuente:

Registro:

Fecha de registro:
Benito Benavente Bizama

65 años

Primer año básico

agricultor

Fundo Maipo (provincia de Arauco, comuna de Curanilahue). Vive ahora en Coihue (comuna de Nacimiento) Aprendió este cuento cuando era niño, de parte de su padre

Constantino Contreras 11/07/ 2001.

Pedro Urdemales era un roto ${ }^{11}$ re-diablo ${ }^{12}$ muy astuto, y ocurrente pu(es). Aunque tuviera algún problema, siempre encontraba la solución. Ése sí que sabía vivir. Una vez se le ocurrió hacerse pasar por un viajero del otro mundo. Por ahí quizás cómo encontró un caballo para ir al pueblo. Lo cierto es que llegó al pueblo y empezó a gritar:

-iQuién quiere mandar reca(d)os pa(ra) el otro mundo! ¡Quién quiere mandar reca(d)os pa(ra) el otro mundo! ¡Aprovechen mi viaje, señores! ¡Aprovechen...! - decía.

Algunos, por curiosidad, se acercaban a averiguar qué quería decir ese hombre. Él les explicaba:

Traigo reca(d)os del otro mundo y llevo reca(d)os pa(ra) arriba también. Llevo encargos para las almas que están padeciendo; muchas están padeciendo. San Pedro no quiere abrirle(s) las puertas del cielo mientras no paguen sus penitencias.

Serían almas que estarían en el purgatorio, padeciendo por sus peca(d)os.

Ya pu(es). Y Pedro, como que estaba apura(d)o pu(es):

- iComo que me voy, como que me encumbro! - decía.

Ya empezaron a correr la voz. Ya empezaron a llegar las viejitas a preguntar por sus parientes muertos; los viudos a preguntar por sus mujeres; unos más jóvenes a preguntar por un hermano, por su abuelito, iqué sé yo!

- Yo traigo y llevo reca(d)os - decía Pedro-. Yo puedo llevar de todo - decía-: cartas, ropa, plata, comida, lo que sea, lo que quieran mandar para esa pobre gente que está sufriendo en la otra vida. Uste(d), señora; uste(d), señor — decía-, su pariente está sufriendo; su ropa está gasta(d)a; ya no le queda

11 roto: en Chile, 'persona de baja condición social' (DHACH: 202).

12 re-diablo: el prefijo re- añade información superlativa al adjetivo, siguiendo una conocida tendencia del habla rural chilena (Oroz 1966: 288). 
na(d)a para comer, no le que(d)a plata ${ }^{13}$ para comprar cigarros, para comprar bebidas. Mándenle un poco de cocavi $1^{14}$ siquiera: un pollito, un pavito asa(d)o, unas chuletitas...

$\mathrm{iJa}, \mathrm{ja}, \mathrm{ja!}$

Y él ya andaba con hambre pu(es). Tenía la guata ${ }^{15}$ medio vacía. Y de nuevo: - iComo que me voy, como que me encumbro!

$\mathrm{JJa}, \mathrm{ja}, \mathrm{ja!}$

- No le crean a ese mentiroso. Las ocurrencias suyas. ¿Quién le va a creer? - decían algunos.

Pero otros se convencían de que eso tenía que ser cierto. Porque Urdemales había averiguado hasta los nombres de algunos difuntos. Había averiguado en el cementerio hasta el año en que había muerto fulano o zutano. Así que las viudas empezaron a llevarle cartas; otras personas le entregaban ropa; otras le entregaban plata. Urdemales iba llenando bolsas no más pu(es).

iJa,ja,ja!

Y había una señora que todo lo daba de a poquito ${ }^{16}$. Y se le había muerto un hijo, un hijo que había sido diablazo ${ }^{17}$, hasta ladronazo habría sido.

-Mi hijo estará sufriendo por todas las maldades que hizo en este mundo - decía la señora.

$\mathrm{Y}$ el viajero ya que completaba su carga.

- ¿Usted podría llevar este paquetito para mi pobre hijo? -le dijo ella.

-Con todo gusto, señora. Al tiro ${ }^{18}$ se lo llevo. Pero dígame qué contiene, para tener cuidado. No se me vaya a quebrar algo por el viaje.

-Es puro cocavi ${ }^{19}$-le dijo-, hace un poco de bulto, pero es que va de todo un poco: un poquito de yerba, un poquito de azúcar, un poquito de sal, un poquito de miel, un poquito de queso, un pollito de fiambre, unos huevitos duros... ja, ja, ja!

- Muy bien -le dijo el viajero-, le llevaré a su hijo este paquete con mucho gusto. Le daré también sus saludos.

El viajero completó su carga y se despidió de la señora. Cuando llegó el marido, ella le contó lo que le había manda(d)o a su hijo.

- ¿Y con quién mandaste esas cosas? —le preguntó él.

13 plata: 'dinero' (DHACH: 181).

${ }^{14}$ cocavi: palabra de origen quechua equivalente a 'víveres o provisiones para un viaje'. El concepto difiere un poco del consignado por la Academia: 'provisión de coca $\mathrm{y}$, en general, de víveres que llevan los que viajan a caballo' (DRAE: I-495).

${ }^{15}$ guata: palabra de origen mapuche equivalente a 'barriga, vientre, panza' (DHACH: 121).

${ }^{16}$ poquito: Cf. Nota 9.

17 diablazo: como en el derivado ladronazo, el sufijo -azo revela tener la vitalidad observada otras veces en el habla rural, para expresar el grado superlativo (Oroz 1966: 288).

${ }^{18}$ al tiro: locución adverbial muy común en Chile (y países vecinos) para expresar los conceptos de 'en el acto, al punto, inmediatamente' (DHACH: 225. Cf. Oroz 1966: 350)

19 cocavi: ver nota 14 . 
- Con ese hombre que va allá pu(es), de a caballo.

Pedro ya iba lejos, saliendo del pueblo.

-Ya, ¿pero cómo se llama ese hombre? ¿Quizás qué bandido será?

- iAy!, se me olvidó preguntarle el nombre — dijo la mujer.

- iNo puede ser, vieja! ¿Tú sois ${ }^{20}$ tonta? - le dijo el marido-. Realmente sois tonta. Y nuestra hija también es tonta. ¡Cómo no preguntarle el nombre! ¡Vamos en seguida a preguntarle cómo se llama!

-Que vaya nuestra hija, mejor — dijo la mujer-. Ella es joven; ella puede correr.

Salió corriendo la cabra ${ }^{21}$ para alcanzar al viajero. Se le hacían humo los pies. Corría, corría, y ya que lo alcanzaba.

— ¡Oiga, oiga! —le decía-. ¡Espere! ¡Espere! ¿Cómo se llama usted? ¡No nos dijo su nombre!

- Yo no tengo nombre - - le dijo Pedro.

- ¿Cómo va a ser eso? - le decía la muchacha-. ¿Cómo no va a tener nombre?

— ¡No tengo nombre! —le dijo Pedro-. ¡Yo no tengo nombre! ¿ No me creís? ${ }^{22}$ Nunca me pusieron un nombre. Pero si quieren reconocerme, pueden identificarme por los rasgos de mi cara. Fíjate bien.

Entonces Pedro Urdemales, se apeó del caballo, se bajó los pantalones y le mostró el trasero a la muchacha. Ja, ja, ja! Por esa cara tendrían que reconocerlo. ¡Ja, ja, ja!

Después volvió a montar en su caballo, picó bien las espuelas y se fue como un rayo, pa(ra) las perdi(d)as. Todavía se andará riendo por ahí. jJa, ja, ja!

\subsection{Las apuestas de Pedro y el gigante}

$\begin{array}{ll}\text { Informante: } & \text { Pablo Hidalgo Larregla } \\ \text { Edad: } & 41 \text { años } \\ \text { Escolaridad: } & 60 \text { año básico } \\ \text { Localidad: } & \text { Carrizal (hijuela Santa Cruz, comuna de Nacimiento) } \\ \text { Actividad: } & \text { labores agrícolas } \\ \text { Fuente: } & \text { aprendió este cuento cuando tenía unos ocho o nueve } \\ & \text { años, de boca de su padre } \\ \text { Registro: } & \text { Constantino Contreras } \\ \text { Fecha de registro: } & 28 / 04 / 2001 .\end{array}$

Esto fue una vez que Pedro Urdimale andaba, andaba por ahí. Pasaba de casa en casa. Entonces no hallaba, una vez, qué hacer Pedro. Francamente no hallaba qué comer, andaba pobrecito. $\mathrm{Y}$ se puso a hacer unas apuestas con un gigante. Entonces ya le dijo el gigante:

${ }^{20}$ sois: forma verbal de segunda persona de plural desplazada a la segunda de singular como parte del voseo.

${ }^{21}$ cabra: nombre metafórico para 'muchacha o mujer joven'. (Cf. DHACH: 72, 'nombre familiar y vulgar que se da a una mujer joven').

${ }^{22}$ creis: forma verbal voseante que remplaza a 'crees'. 
-Oye, Pedro - le dijo-, me han dicho que tú $\operatorname{sos}^{23}$ muy gallo ${ }^{24}-$ le dijo- ${ }^{25}$. Y sos harto gallo. ¿No es cierto?

-No - le dijo-, no.

- Sí, sos harto gallo - le dijo- Pero - le dijo— vamos a hacer seis apuestas y, si me ganás las seis apuestas — le dijo—, te las pago; y si no - le dijo-, te va a costar tu vida. Tú vas a ser muerto. Y si perdís - le dijo- alguna, vas a ser muerto. Yo te voy a matar.

Entonces Pedro dijo:

- iCómo me va a matar!

Empezó... le dijo:

- Mira - le dijo-, un día vamos a hacer una apuesta. Vamos a ir al bosque -le dijo- y quién trae más leña -le dijo- ¿ah?

Fueron al bosque. Había un bosque grande. Ya fue el gigante; trajo un braza(d)o ${ }^{26}$ de leña; trajo como dos carreta(d)as de leña, como era un gigante ¿ah?; tremendo braza(d)o de leña que trajo. (En)tonces llegó:

-iYa! -le dijo-, ahora te toca a tú ${ }^{27}$, Pedro.

Y siempre (a) Pedro lo jue ${ }^{28}$ echando a(d)elante, a(d)elante.

-iYa! -le dijo-, ahora te toca a tú. betas? ${ }^{30}$

- iYa pu(es)! -le dijo-. Mire, mi gigante ${ }^{29}$-le dijo-, ¿tiene -le dijo- unas

${ }^{23}$ sos: variante de sois (Cf. nota 19). Otras formas verbales voseantes empleadas en el mismo texto son: ganás, perdís, llevís y matís. En general, estas variantes son empleadas especialmente en el discurso de los personajes.

${ }^{24}$ gallo: metáfora popular en Chile para referirse al 'hombre fuerte, destacado, valiente, emprendedor' (DHACH: 115). Rasgos como la 'destreza' y la 'osadía' caben también dentro de esta expresión. Además, suele emplearse galla para referirse a la mujer que presenta tales cualidades. Ser un gallina, en cambio, es expresión que conviene a 'quien no se atreve a enfrentar una situación difícil, quien no se arriesga'.

${ }^{25}$ dijo, le dijo: Uno de los rasgos de textualización más recurrentes en todas las narraciones del corpus es la reiteración (muchas veces redundante) de los verba dicendi, que, como se sabe, contribuyen a distinguir el habla de los personajes con respecto al discurso del narrador.

${ }^{26}$ brazado: Se emplea aquí con el significado muy castizo de 'cantidad de leña, palos, bálago, hierba, etc. que se puede abarcar y llevar de una vez con los brazos', sinónimo de brazada (DRAE: I-322).

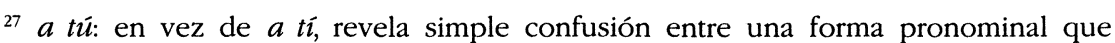
ha de usarse sin preposición (para la función de sujeto) y otra que siempre ha de llevar preposición (para la función de complemento verbal).

${ }^{28}$ jue: La velarización de la consonante labiodental $[\mathrm{f}]>[\mathrm{x}]$, en fue $>$ jue por influencia de la vocal velar siguiente, en este caso la semiconsonante [w] del diptongo [we], es un rasgo bastante común en el castellano popular de Chile (Cf. Oroz 1966: 150).

${ }^{29}$ Mire, mi gigante: Nótese el empleo del posesivo $m i+$ sustantivo común como forma de tratamiento para dirigirse a un superior. Este rasgo es muy usado en el habla policial y de las milicias ( $m i$ comisario, $m i$ sargento), pero también se usa como forma vocativa en el habla amical ( $\mathrm{j} M i$ compadre, tanto tiempo...' ;Hola, mi amigo!).

30 beta: en su acepción de 'pedazo de cuerda o hilo'. La forma alternativa en la escritura es veta (DRAE: II-2083). 
-Sí -le dijo-, tengo.

¡Ya! Le pasó unas betas por ahi. Y Pedro siguió envolviendo el bosque pu(es) ¿ah? Le puso lazo en un árbol y siguió de vuelta y vuelta.

- ¡Oye, Pedro!, ¿qué es lo que vas a hacer? -le dijo.

- Lo que voy a hacer - le dijo- es que voy a... tengo que llevarme to(d)o el bosque pu(es) - le dijo-, to(d)o se lo voy a llevar.

${ }_{-}$No, Pedro! - le dijo-, te pago la apuesta - le dijo- y no me llevís el bosque, porque después ¿qué voy a hacer de leña? -le dijo- Me vas a llevar to(d)o el bosque ¿y qué voy a hacer de leña? Te pago la apuesta.

-Ya.

Ganó la apuesta pu(es).

Ya.

Después le dijo:

- Ahora - le dijo- vamos a ir a la otra. Mira - le dijo-, vamos a ir a buscar toda el agua que podamos - le dijo- a la laguna que tengo.

Tenía una laguna el gigante.

Entonces ya fue. El gigante trajo una pipa; se la echó la pipa al hombro iy partió miércales! ${ }^{31}$ Y se la llenó de agua y se fue con ella pa(ra) la casa pu(es). Después ya le dijo:

-iYa!, ahora te toca a tú, Pedro.

- ¡Ya! - le dijo- ¿Y tiene pala?, ¿tiene picoto? ${ }^{32}$

-Sí -le dijo.

Ya se fue Pedro y se ganó al la(d)o de la laguna y empezó a hacer canal, a hacer canal por todos la(d)os. Y le dijo:

- ¿Qué vas a hacer, Pedro?

- Na(d)a pu(es) - le dijo-, es que yo voy a secar y llevar toda la laguna de agua pu(es) -le dijo.

- iNo, Pedro! -le dijo-, no te llevís la laguna de agua -le dijo-. ¿Y qué voy a hacer con mi sed yo después? -le dijo-. ¡Déjame la laguna ahi! ¡Te pago la apuesta!

Ya llevaba dos apuestas gana(d)as pu(es). Se las ganó.

Ya después le dijo:

- Mira, Pedro - le dijo-, ahora vamos a ir a la otra. Vamos a ir al la(d)o de la laguna (y habían ${ }^{33}$ piedras ahí, al la(d)o de la laguna). ¿Quién hace pedazos - le dijo - una piedra! Mañana va a ser la apuesta - le dijo: ¡quién hace pedazos una piedra aquí en la mano!

Ya se fue. Pedro se fue calla(d)ito y fue a ver a una abuelita que hacía quesillos por ahi. Consiguió uno; lo hizo una pelota, más u menos ${ }^{34}$ como piedra, y la dejó al la(d)ito, ahí, de la laguna, algo tapa(d)ita con arena.

31 jmiércales!: forma eufemística común por '¡mierda!', usada para expresar desagrado o reprobación o simplemente para reforzar una idea.

${ }^{32}$ picoto: por pico o zapapico (DRAE: II-2124), 'herramienta de punta aguda de hierro para cavar las partes duras de un trozo de tierra'. En el habla rural se suele emplear también la forma femenina de esta palabra: picota.

33 habian: Este uso de la forma de plural en vez de la impersonal habia (para indicar existencia de) es bastante común, explicable por la tendencia a hacerla concordar con el complemento directo.

${ }^{34}$ más $u$ menos: La vocal $o$ tiende a cerrarse en $u$ en este contexto adverbial. 
(En)tonces va el gigante y toma una piedra y la hizo arena aquí pu(es), la partió, la hizo arena.

-iYa!, ahora te toca a tú, Pedro - le dijo.

Llegó Pedro y va, y justamente (d)onde estaba la pelota del quesillo, ahí, y la toma aquí y la hizo harina y le estiló el jugo.

— iMe la ganaste, Pedro! - le dijo-. ¡Ya!, me la ganaste otra vez...

Después le dijo el gigante:

- Vamos a ir a la otra ahora. Mira - le dijo-, mañana — le dijo- vamos a tirar una piedra ¿ah?: quién la tira más lejos - le dijo.

Entonces ya Pedro no halló qué hacer:

- ¿Qué voy a hacer? ¿Qué voy a hacer?

Siguió pensando. Como era al otro día, hizo una trampita por ahí, como pudo, y que no, en la trampita cayó un burrión ${ }^{35}$ pu(es). (En)tonces lo tenía ahí su burrión, Pedro, meti(d)ito en la cartera. Y lo tenía ahí el burrioncito. Y ya llegó el gigante tiró la piedra. iQué!, dio vuelta un cerro pu(es).

- iYa!, ahora te toca a tú, Pedro - le dijo.

Ya Pedro llegó y le hizo y le hizo la puntería... y dispara: ¡Qué!, el burrioncito se fue... una loma, otra loma.

-iMe la ganaste, Pedro, otra vez! -le dijo-. ¡Puta - le dijo-, me la ganaste! Ya.

-Mañana - le dijo— vamos a ir a la otra: ¿Quién — le dijo— le paga un puñete a un roble y dentra ${ }^{36}$ más allá! —le dijo- ¿ah?

Y él le demostró ${ }^{37}$ cuál era el árbol pu(es) ¿ah? (En)tonces Pedro por ahí se fue antes y le hizo un agujero al roble, todo lo que cabía la mano, y le dejó la cascarita ahí puesta. Llega el gigante al otro día y le pone el combo ${ }^{38}$ al roble. ¡Qué!, se le reventó la mano. Y no anduvo na(d)a mucho pu(es). ¡Va Pedro y le pone el combo!... Le dentró hasta el codo...

—iPuta que me la ganaste, Pedro, otra vez! —le dijo (jJa, ja, ja!)—. ¡Pero, puta, Pedro! -le dijo.

Ya, se la ganó.

Después le dijo:

- Mira, Pedro - le dijo-, ahora vamos a ir a la última - le dijo-. Y si te gano ésta —le dijo-, estás mal; y si no, estás bien —le dijo- Ya - le dijo-, vamos a tirar una lanza mañana — le dijo-. ¿Quién la va a tirar — le dijo— más lejos!

Llega el gigante al otro día. Toma una lanza y la tira. ¡Puta!, llegó harto lejos pa(ra) allá pu(es).

Y ya Pedro le dijo:

${ }^{35}$ burrión: variante fónica de gorrión; lo corrobora luego la forma diminutiva burrioncito.

${ }^{36}$ dentrar. es forma que perdura como antigua variante de entrar (Cf. Oroz 1966: 343, 368).

37 demostrar: 'mostrar'.

${ }^{38}$ combo: en este contexto se usa con la acepción chilena (y peruana) de 'puñetazo' (DRAE: I-515). 

mamá?

— Mire, mi gigante — le dijo—, ¿adónde usted — le dijo— tiene la... tiene su

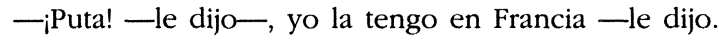

— ¡Ya pu(es)! -le dijo.

Y empezó Pedro y tomó la lanza y la batía aquí; le decía:

— iLanza, lanza, ándate pa(ra) Francia!... ip(or d)onde la madre del gigante, a atravesál.le ${ }^{39}$ la panza!

- ¡No, Pedro! ¡No, no, no! ¡No, Pedro! ¡Te pago la apuesta! ¡Y no me matís (a) mi mamá! ¡Cómo me vas a matar (a) mi mamá!

¡Ja, ja, ja! Así que de ahi se terminó pu(es). Se terminaron las seis apuestas. $\mathrm{JJa}, \mathrm{ja}, \mathrm{ja}$ !

\subsection{La burla de Pedro Urdemales}

Narrador:

Edad:

Escolaridad:

Actividad:

Localidad:

Fuente:

Registro:

Fecha de registro:
Mauricio Máximo Cid Campos

43 años

Nunca asistió a la escuela, pero sabe leer

labores agrícolas

Los Patos (comuna de Nacimiento)

Aprendió este cuento cuando era ovejero y tenía unos dieciocho años de edad, de parte de Pedro Gallardo, un mozo de fundo y buen narrador

Constantino Contreras

$06 / 04 / 2001$.

Entonces tal vez Pedro Urdemales compró una gallina, o se la regalaron. Y, como tenía que andar un largo camino, esa gallina llevarla al brazo le era molesto ¿no? Entonces pasó a una casa y le dijo al caballero:

-Quiero dejal.le ${ }^{40} \mathrm{mi}$ gallina encarga(d)a - le dijo-, porque ya voy molesto con ella. Cuando vuelva a pasar, no muy lejos de hoy día, la paso a buscar pu(es).

-Bien -le dijo el caballero.

Entonces siguió su camino y la gallina quedó ahí pu(es). Entonces se descuidaron dónde iba a dormir la gallina. Entonces la primera noche no se fue a echar así (d)onde había un chiquero (d)onde se iba a echar un chancho que tenían, grande. Entonces llegó la noche: la gallina temprano se fue a poner ahí; y el chancho llega y se echa encima de la gallina.

$\mathrm{Al}$ otro día dijo el caballero:

- ¿Dónde quedaría la gallina del hombre que pasó a dejal.la? ¿Dónde dormiría por ahî? Busquémosla, no sea que vaya a pasar la chilla (porque había mucha chilla ${ }^{41}$ ) y ésa la va a cazar.

${ }^{39}$ La consonante vibrante simple $r$ se suele lateralizar cuando le sigue una consonante lateral.

${ }^{40}$ Cf. nota 39.

${ }^{41}$ chilla: palabra de origen mapuche para denominar una especie de zorro pequeño del sur (Dusicyon griseus maulinicus) (Cf. DHACH: 91). 
No la encontraron. Buscaron por aquí, por allá. Fueron a mirar el chiquero. La gallina estaba torcidita, adonde el chancho se había echa(d)o encima de ella. Entonces, ya.

—¿Qué vamos a hacer, vieja? -le dijo—. La gallina está muerta; el chancho se echó encima de ella.

Entonces le dijo:

—iLa pelamos y la $\operatorname{comimos}^{42}$ pu(es)! Y cuando pase, le pagamos la gallina.

Así, de acuerdo. Cuando no tardó mucho en pasar a buscar la gallina el hombre. Y se excusó el caballero. Le dice:

- Tuvimos desgracia en la gallina pu(es). No pusimos cuida(d)o. Se fue a echar al chiquero del chancho y el chancho llegó tarde en la noche y se echó encima de ella. La mató pu(es). Tuvimos que comel.la. Bueno, ahora se la vamos a pagar.

-No - le dijo-, tienen que darme el chancho - le dijo.

- ¿Cómo?

-Pero si el chancho la mató, así es que el chancho tiene que dármelo. jJa, ja, ja!

Así que ya el hombre era un poco justo. Al cabo de un rato le dijo:

-Ya, llévese el chancho, (s)iñor ${ }^{43}$-le dijo-, pero nunca más me pase a dejar encargos.

Ya. Anduvo harto con el chancho. Al fin el chancho se cansó. Ya también él iba molesto con el chancho. Pasa a otra casa. Le rogó también al dueño de casa que le recibiera el chancho de encargo para... porque ya iba cansado el chancho y más él, lidiando con él.

-Bien —le dijo el hombre-, déjelo.

- Yo no tardo mucho en volver a pasar pa(ra) lleval.lo.

Entonces llega y se va.

Y tenía una hija el caballero.

- Tan lindo el chancho del hombre — dijo- (Pasó una semana y no pasaba). Comámonos el chancho, papá. Y se lo compramos, se lo pagamos.

Y le cargosió y le cargosió ${ }^{44}$ :

- Comámonos el chancho. Yo tengo plata y yo pongo un tanto por el chancho.

El caballero se tentó también pu(es). Han matado el chancho. Y se lo siguieron comiendo. ¡Y no aparece el dueño de nuevamente ${ }^{45}$ ! Y el caballero le sigue contando de que... ${ }^{46}$

- Me aburrió mi hija - le dice-, que quería comer el chancho, que ella tenía plata $^{47}$, que, en fin, ayudaba a pagar el chancho. Ya me aburrió. Así que tuvimos

42 comimos: vid. nota 8.

43 ( $s$ )iñor. variante popular de señor, como forma de tratamiento que revela confianza (Cf. Oroz 1966: 292-293, iñor / iñora).

44 cargosiar. variante antihiática de cargosear, que, en Chile y países vecinos, equivale a 'importunar, molestar' (DRAE: I-414).

45 de nuevamente: es con seguridad un cruce entre las formas adverbiales de nuevo y nuevamente.

46 de que: expresión incompleta, pero con un evidente empleo del dequeísmo.

${ }^{47} \mathrm{Cf}$. nota 13. 
que hacel.lo pu(es). Y ahora, lo que nos cobre uste(d), le pagamos por su chancho pu(es).

- Bien - le dijo—, si la niña fue la autora — le dijo-, me tiene que dar la niña.

Así que fue ganando él en el negocio.

Entonces ya ipucha ${ }^{48}$ !, por ahí to(d)o perplejo:

- ¿Y cómo le vamos a dar la hija a este hombre pasajero?

Entonces ya consultas por aquí y pa(ra) allá. Y el hombre decía:

-No, tiene que darme la niña no más.

Entonces la niña decía:

-Papito ${ }^{49}$, bueno, hágale el gusto. Y yo, cuando vaya bastante lejos pa(ra) allá, yo me libero de él por el campo y me vuelvo. Y ustedes van a mi encuentro para... Y el hombre, al último, ahora, no lleva na(d)a - le dijo-, porque él no recibe plata.

Así que la pensó bien la niña. Pero el hombre llevaba un tremendo saco. Así que anduvo bastante y la iba maliciando que la niña se le iba a liberar pu(es), porque la niña miraba pa(ra) todos la(d)os y tenía esa intención pu(es).

Entonces ya, vivaracho también Pedro Urdemales, llega y echa la niña al saco pu(es) y se la planta al hombro. Y siguió. Claro que la niña ipucha ${ }^{50 !}$ ahí se vio turbada, lloraba a(d)entro del saco. Y el otro le prometía:

-No, si conmigo no lo va a pasar mal - le dijo-. Yo tengo bendiciones en mi hogar.

Y la iba conformando.

- ¡Suélteme!, ¡suélteme!

¡Y no hay un negocio en una parte!...

-Mire, m(i) hijita ${ }^{51}$, voy a pasar a comprar de to(d)o aquí, más encima: azúcar, yerba, pan y cuanta cosa pa(ra) llegar al hogar y servirse de to(d)o.

Pero ella ipucha! lloraba, lloraba adentro. Así que llegó al sitio donde estaba el negocio. Y el saco, bien amarra(d)o pu(es). Entonces no deja el saco lejitos ${ }^{52}$ y él fue a meterse ahí, al negocio. Y cuando ella escucha que una señora andaba por ahí, de la casa, empleada sería...

— ¡Sáquenme!, ¡sáquenme! —empezó a clamar-, ¡sáquenme, ipor favor!, ¡auxilio!

Y la señora, novedosa:

—¿Quién es?

Ya la niña le decía:

- Me llevan a la mala. ¡Sáquenme!.

Entonces la señora llega ahí y empieza a desatar el saco: era una niña.

Ya.

Ya la niña le dijo:

48 ipucha!: forma exclamativa eufemística por 'iputa!'

${ }^{49}$ papito: forma afectiva para referirse al 'padre'.

${ }^{50}$ Cf. nota 48.

$51 m(i)$ hijita: forma muy íntima para tratar a una mujer, especialmente cuando es muy atractiva.

52 lejitos: ver nota 10. 
- Si me llevan a la mala. ¡Sáqueme por favor!

-Ya, vaya a esconderse, pa(ra) allá váyase.

Entonces iy no ${ }^{53}$ hay una perra echa(d)a en el patio, durmiendo! Y la señora va con el saco con la boca abierta. Le pone por el la(d)o de la cabeza, así, y le da una pata(d)a por detrás a la perra. La perra se para y se mete más bien al saco pu(es). Y la señora le apreta ${ }^{54}$ la boca arriba y le amarra la cuestión. Y ahí le deja la perra amarra(d)a, a(d)entro (d)el saco. Y ya ella fue a juntarse con la niña pa(ra) protegel.la más, para defendel.la. Entonces en ese ratito ya termina el hombre de comprar y sale para ver su saco. Claro, se movía la perra a(d)entro. Ya le dijo:

-iVámonos, m(i) hijita! -le dijo.

Y la perra gimía ${ }^{55}$ a(d)entro pu(es). La linda deseaba salir. ja, ja, ja! Entonces le decía:

-No - le decía-, llevo de to(d)o: llevo queso, llevo pan, llevo azúcar, yerba, no sé qué más.

Así que decía eso para tranquilizar no más a la niña, a(d)entro del saco. Se puso la bolsa al hombro y siguió andando. Y la perra gimía y gimía, pero ya no le hablaba tampoco, porque la niña es que lloraba no más.

Entonces ya ipucha! cansado llegó a su casa. Así que:

- Ahora es la mía — dijo el hombre.

Desata el saco para sacar (a) la niña pu(es). En cuanto abre el saco, la perra dio un salto. jJa, ja, ja! Y se le escapa. Y el otro:

—iY qué! ¡Ésta es una mujer bruja, que se volvió perra! ¡Esta mujer!

¿Qué más iba a rogal.le pu(es), si ya era un animal pu(es)?

Pero la habilidad de la señora de poner la perra a(d)entro del saco. jJa, ja, ja! Ahí la sacó mal Urdemales, porque él hacía leso ${ }^{56}$ al mismo demonio, pero esta vez fue burlado por una mujer.

\section{ABREVIATURAS}

DHACH = ACADEMIA CHILENA correspondiente de la Real Academia Española: Diccionario del babla chilena, Santiago de Chile, Universitaria, 1978.

DRAE = REAL ACADEMIA ESPAÑOLA: Diccionario de la lengua española, vigésima primera edición, Madrid, Espasa Calpe, 2 vols., 1992.

OROZ = OROZ, Rodolfo: La lengua castellana en Chile, Santiago de Chile, Universitaria, 1966.

${ }^{53}$ Cf. nota 6. Reaparece el uso positivo de la forma negativa no: a... no deja el saco lejitos" = 'deja el saco lejos'; "iy no hay una perra echa(d)a en el patio...!n = 'iy hay una perra echada en el patio!'.

${ }^{54}$ apreta: variante morfológica de aprieta, por la tendencia a regularizar las formas verbales irregulares.

55 gimía: variante fónica de gemía, por asimilación vocálica.

${ }^{56}$ hacer leso a uno: locución verbal familiar equivalente a 'engañar' (DHACH: 132). 


\section{BIBLIOGRAFÍA CITADA}

BEINHAUER, W. 1973. El bumorismo en el español hablado. Madrid: Gredos.

Camarena, J. 1995. "El cuento popular". Anthropos 166/167: 30-33. Número dedicado a la Literatura Popular.

CERDA-Hegerl, P. 1996. Fronteras del Sur. La región del Bío-Bío y la Araucanía chilena 1604-1883. Temuco: Ediciones Universidad de La Frontera.

Chevalier, M. 1978. Folklore y literatura: El cuento oral en el Siglo de Oro. Barcelona: Crítica.

Contreras, C.; E. Barraza y P. Álvarez-Santullano. 1995. Cuentos orales de adivinanzas. Selección, estudio y notas, Santiago de Chile: Universitaria.

COROMINAS, J. 1990. Breve diccionario etimológico de la lengua castellana. Madrid: Gredos, 3.ª ed., 5. reimpresión.

Dannemann, M. 1985. "Estudio y selección de cuentos de Chile", en Cuento popular andino, tomo 2 (Colombia, Chile, Venezuela): 141-212. Quito: Ediciones IADAP.

Dijk, T. van. 1992. La ciencia del texto. Barcelona: Paidós, 2. a reimpresión. Trad. del holandés por Sibila Huzinger.

LAVAl, R. A. 1997 [1925]. Cuentos de Pedro Urdemales. Santiago de Chile: LOM Ediciones, 3. ${ }^{\mathrm{a}}$ ed.

MONTEMAYoR, C. 1998. Arte y trama en el cuento indígena. México: Fondo de Cultura Económica.

Pino SaAvedra, Y. 1963. Cuentos foklklóricos de Chile. Santiago de Chile: Universitaria, T. III.

PINON, R. 1965. El cuento folklórico (como tema de estudio). Buenos Aires: EUDEBA.

PISANTY, V. 1995. Cómo se lee un cuento popular. Barcelona: Paidós. Trad. del italiano por Juan C. Gentile Vitale.

Propp, V. 1981. Morfología del cuento. Madrid: Fundamentos, 5.․․ ed. Trad. de Lourdes Ortiz.

SALAS DE LECUNA, Y. 1985. El cuento folklórico en Venezuela. Antología, Clasificación y Estudio. Caracas: Biblioteca Nacional de la Historia.

SAvJ-López, P. 1917. Cervantes. Madrid: Calleja. Trad. del italiano por Antonio G. Solalinde.

SepúlVEDA, F. 1987. "El cuento folklórico: una vía al ser". Aisthesis 20: 45-69.

THOMPson, S. 1972. El cuento folklórico. Caracas: Universidad Central de Venezuela. Trad. de Angelina Lemmo.

VALDÉs B., R. 1987. "La imagen del Hombre en el cuento". Aisthesis 20: 23-26.

VÉLEZ, A. L. 1992. "El enigma del molinero'. Reflexiones sobre los cuentos de adivinanzas", Revista de Folklore XII: 147-155. Publicado también en la revista electrónica Atbenea /www.athenea.es.org/. 